\title{
Retaining the patient perspective in the International Classification of Functioning, Disability and Health Core Set for low back pain
}

\author{
Cecilie Røe ${ }^{1,2}$ \\ Unni Sveen' \\ Erik Bautz-Holter ${ }^{1,2}$ \\ 'Department of Physical Medicine \\ and Rehabilitation, Ulleval University \\ Hospital, Oslo, Norway; ${ }^{2}$ Faculty \\ of Medicine, University of Oslo, \\ Norway
}

Objective: To examine the relationship between health problems as rated by the health professionals in the Norwegian form of the Core Set for low back pain and the patients' self-reported health problems in Oswestry Disability Index (ODI) and World Health Organization Disability Assessment Schedule II (WHODAS II).

Methods: This was part of an international multicenter study where a convenience sample of 118 Norwegian patients with low back pain (LBP) participated. The ICF Core Set for LBP was filled in by the health professionals. The patients reported their health problems in the WHODAS II and ODI. The items in WHODAS II and ODI were linked to the ICF. The problems reported in WHODAS II and ODI were compared to the problems scored by the health professionals in the linked ICF categories in the Comprehensive ICF Core Set for LBP.

Results: All items in ODI could be linked the ICF. Four items in WHODAS II could not be linked to the ICF and additionally two items could not be linked to specific ICF categories. All ICF categories linked to the ODI were included in the Comprehensive Core Set for LBP, whereas six items in WHODAS II could not be linked, and additionally 11 of the items were not represented in the Core Set. With the exception of sexual function, above three quarter of the patients' reported problems within body functions was captured by the health professionals. Within several of the activities and participation categories the health professionals scores in the ICF reflected the patients' reported problems well. Surprisingly some of the problems in activities of daily living were poorly reflected.

Conclusion: The Comprehensive ICF Core Set for LBP covers most of the items in ODI and WHODAS II in areas where patients report significant problems, with some exceptions. The subjective dimension related to the impact of the health condition as well as the feeling of being a burden to their family appeared to be important to these patients and not covered in the ICF. Problems with sexual functions and relationship were poorly reflected in the health professionals' scores in the Comprehensive ICF Core Set for LBP. In clinical practice it is a challenge to assess the individual patients' broad spectrum of problems precisely.

Keywords: low back pain, WHODAS II, ICF, musculoskeletal disorders

\section{Introduction}

Low back pain (LBP) represents the most frequent condition among musculoskeletal disorders (Bongers et al 1993). Lifetime prevalence of low back pain is reported to be up to $84 \%$ and point prevalence up to $33 \%$ in the western countries (Natvig and Picavet 2002; Jeffries et al 2007). These patients experience pain, positioning and mobility problems with impact on their daily activities, and subsequently restrictions in participation in leisure, work and social life (Brage 1998).

The LBP patients' problems with physical function are captured by the traditional outcome measurements (Guyatt et al 1993; Daltroy et al 1996; Roland and Fairbank 2000). However, the spectrum of problems within activities and participation, and the 
influence of the environment are generally poorly covered (Cieza et al 2005; Sigl et al 2006). The approval of the new International Classification of Functioning, Disability and Health (ICF), represents a globally agreed framework and classification of the wide spectrum of problems related to chronic health conditions (WHO 2001). However, the whole classification is not feasible for use in clinical practice. Hence, disorder-specific ICF Core Sets were developed in several areas, including LBP (Cieza et al 2004). These ICF Core Sets are now undergoing worldwide testing.

Retaining problems experienced by the patients themselves in the development of classifications or measurements is regarded as important, and should be looked upon as one element of the patient perspective. The broad evaluation of functioning and disability (Ueda and Okawa 2003) represented by ICF is a promising tool in this respect. However, the development of the ICF Core Sets for chronic conditions with a tenfold reduction of the number of categories may reduce the possibility to detect the individual problems. The Comprehensive ICF Core Set for LBP containing 78 categories within body functions and structure, activities and participation may therefore lack some of the LBP patients' problems.

Thus, in the development of a Comprehensive ICF Core Set for LBP one should address to which extent the most important problems reported by the patients are represented. Among the most frequently used self-reporting LBP specific measurements is the Oswestry Disability Index (ODI). This instrument covers aspects within body functions and to some extent activities (Fairbank and Pynsent 2000). In order to obtain a wider perspective of problems within activities and participation, the generic instrument World Health Organization Disability Assessment Schedule II (WHODAS II 2001) has been used.

Another approach when the patients' self-experienced problems are to be identified (Grill et al 2005) is focus groups or interviews. These methods were not part of the process when the present Comprehensive Core Set for LBP was developed (Cieza et al 2004). Mullis and colleagues (2007) interviewed 402 patients with LBP and compared the problems contained in their statements with the ICF categories included in the ICF Core Sets for LBP. They found that the patients' main problems were contained in the Comprehensive ICF Core Set. However, in Mullis study, the Comprehensive ICF Core Set was not filled in by the health professionals, hence comparison between problems reported by the patients and scored by the health professionals in a clinical setting were not covered. By linking the ICF to the items in outcome measurements like ODI and WHODAS II, comparison of the scores of health professionals in the ICF Core Set with the patients self-reported scores on similar problems can shed light on this issue.

Hence, the present study aimed to explore whether the patients' problems were retained in the Comprehensive ICF Core Set for LBP by assessing:

- whether the ICF categories linked to the WHODAS II and ODI were covered in the Comprehensive ICF Core Set for LBP;

- whether the problems reported by the patients in ODI and WHODAS II were captured by the health professionals' scores in the Comprehensive ICF Core Set.

\section{Material and methods}

\section{Study design}

The study was a multicenter, cross-sectional, prospective study involving four study centers in Norway. The Norwegian study was also part of the international validation study performed by the ICF Research Branch WHO Collaborating Centre for the Family of the International Classification of ICF at the Ludwig-Maximilian University in Munich, Germany.

\section{Inclusion}

The recruitment of the patients and ICF-based data collection were performed by physicians and other health professionals (physiotherapists and nurses) trained by researchers at Ulleval University Hospital, Oslo, Norway. All participating persons were experienced health professionals working with LBP patients. The eligible population was LBP patients attending specialist in physical medicine and rehabilitation at the four study centers. A convenience sample of patients were included if they were at least 18 years old, had sufficient knowledge of the Norwegian language, and the purpose and reason for the study was understood. The exclusion criteria were unhealed wounds and other diseases dominating the loss of functioning. The patients signed an informed consent. The study was approved by the Regional Committee for Medical Research Ethics in Health Region East.

\section{Measures}

The ICD-10 diagnosis, the number of surgical interventions and hospitalizations due to LBP, as well as whether the pain was acute ( $<4$ weeks), subacute ( 4 to 12 weeks) or chronic $(>12$ weeks) was documented for each patient.

The ICF-based data were collected using the Comprehensive ICF Core Set for LBP, including 78 ICF categories [11]. 
The ICF categories were designated by the letters b (Body functions, 19 categories), (Body structures, 5 categories), $\mathrm{d}$ (Activities and participation, 29 categories), and e (Environmental factors, 25 categories). To evaluate the extent of the patient's problem in each of the 78 ICF categories contained in the Comprehensive ICF Core Set for LBP, a generic qualifier scale was used. The qualifier scale of the components Body functions, Body structures and Activities and participation has five response categories, each ranging from 0 to $4:$ no/mild/moderate/severe/complete impairment or difficulty. The qualifier scale of the component Environmental factors has nine response categories ranging from -4 to +4 . A specific environmental factor can be a barrier ( -1 to -4$)$, a facilitator (1 to 4$)$, or may have no influence (0) on the patient's life. If the factor has an influence, the extent of the influence (either positive or negative) can be coded as mild/moderate/severe/complete. In addition, there are the response options " 8 - not specified" and " 9 - not applicable" [8].

The Oswestry Disability Index (ODI) is a self-report questionnaire, assessing pain and problems with functioning related to LBP in 10 domains scored on a 6 point Likert scale with separate wording for each domain (Roland and Fairbank 2000). The domains represent pain intensity, personal activities of daily living, lifting, walking, sitting, standing, sleeping, sexual activity, social activity and traveling. The validated Norwegian version was used (Grotle et al 2003).

The World Health Organization Disability Assessment Schedule II (WHODAS II) is a self-report questionnaire containing 36 items scored on a 5 point Likert scale from no problems to very large problems/cannot perform. WHODAS II (2001) is validated in order to assess daily functioning within the following six domains; communication, mobility, self-care, interpersonal, life activities, and participation.

\section{Linking ICF to WHODAS II and ODI}

In order to compare the content, the items in ODI and WHODAS II were linked to the ICF classification according to the procedures described by Cieza and colleagues (2005). One occupational therapist and one physician performed the linking between the ICF and ODI and WHODAS II. The two professionals performed the linking independently of each other. As the ICF Core Set for LBP comprises categories at the second level, the linked categories were assigned to the second level. Subsequently the health professionals discussed the proposed categories and reached consensus about the final linking. It was then assessed whether these categories were contained in the Comprehensive Core Set for LBP.

\section{Data analysis and statistics}

The percentage agreement between the two health professionals in the linking of ICF at the second level to ODI and WHODAS II is reported. The patients' answers in ODI and WHODAS II were dichotomized for each item with 0 representing no problem and all other scores representing a problem. The percentage of patients reporting a problem in ODI/WHODAS II is reported. The health professionals' scoring in the Comprehensive ICF Core Set for LBP is also categorized for each category with 0 representing no problem and all other scores representing a problem.

The percentage of patients who were scored by the health professional as having problems in the ICF categories contained in the Comprehensive ICF Core Set for LBP are also given. The percentage of the problems reported by the patients that were captured by the health professionals' scores in each category of the Comprehensive ICF Core Set were calculated. When the ICF categories were linked to several items in ODI and WHODAS II, correspondence for each item is given within the components of body functions, activity and participation. Confidence intervals (CI) are also calculated for all the percentages. Even though some of the environmental categories could be linked to items in ODI and WHODAS II they are only related to the problems and not actually representing them. Thus, we did not find it meaningful to compare the subjects reported problems in the items in ODI or WHODAS II to the scored problems in the linked environmental categories. Median duration of disease with interquartile range (IQR) is given. Mean ODI score and standard deviation (SD) is given. Data analysis was undertaken using Statistical Package for the Social Sciences (release 14.0; SPSS, Inc., Chicago, IL).

\section{Results}

The patients mean age was 47 (SD 12) years, 52\% $(n=63)$ women participated. Twenty three subjects lived alone, and $50 \%$ of the subjects were retired due to LBP. Seventy six percent had chronic, $13 \%$ acute and $11 \%$ subacute LBP. Forty eight percent were outpatients, 44\% inpatients and $8 \%$ day clinic patients. One percent had three or more surgical interventions, $75 \%$ had had no surgery. Median duration of LBP was sxi months (IQR 45 months). Six percent had radiculopathy (ICD 10 classification M54.1), 4\% sciatica (M54.3), 18\% lumbago with sciatica (M54.4), 64\% LBP (M54.5) and 8\% spinal stenosis (M48.0). Twenty three percent had had at least one surgical intervention due to LBP and $62 \%$ had been hospitalized once due to LBP. Thirteen percent of the patients had acute, 
$12 \%$ subacute and $76 \%$ chronic back pain conditions. The mean ODI score for the present population was $33 \%$ (SD 12\%).

\section{Linking ICF to WHODAS II and ODI}

All together 56 categories in the ICF were linked. Nineteen categories were linked to ODI, covering all its items. Forty seven categories were linked to WHODAS II, covering 30 of the 36 items in WHODAS II. For ODI the two raters agreed on $89 \%$ of categories. That is, seventeen of the categories for ODI were suggested by both health professionals, and two additional categories included after the consensus. For WHODAS II, the raters agreed on $91 \%$ of the categories, with 43 categories suggested by both health professionals. Seven categories were not originally suggested from both health professionals, of these, four were included after consensus.

The items in WHODAS II that was not linked to ICF were Staying by oneself within the Self-care domain which did not represent any substantial problem for this LBP population. However the other five non-linked items were within the Participation component and represented considerable problems for these patients (Table 1).

\section{Linked ICF categories covered by the Comprehensive ICF Core Set for LBP}

For ODI, all the linked ICF categories were contained in the Comprehensive ICF Core Set for LBP (Tables 2 and 3). Twenty four of the 47 linked categories were contained with respect to WHODAS II. As several of the items in WHODAS II were linked to more than one ICF category, this resulted in additionally 11 items in WHODAS II not being covered by the Comprehensive ICF Core Set for LBP (Tables 2, 3 and 4). The frequency of reported problems by the patients for the items in WHODAS II not contained in the Comprehensive ICF Core Set for LBP ranged from 3 to $53 \%$ (Tables 2, 3 and 4). Most important was that 53\% of the patients reported problems with remembering to do important things and 50\% with finding solutions to problems in daily life. These problems may be linked to ICF categories b144 Memory functions and b164 Higher-level cognitive functions, which were not included in the present ICF Core Set. Within the environmental factors The ICF categories e115 Products and technology for personal use in daily living and e520 Open space planning, services and polices were not included in the Core Set, but only the latter represented a problem to the present patients (Table 4).

\section{Correspondence of patients reported problems in ODI and WHODAS II and the health professionals' scores in the Comprehensive ICF Core Set \\ for LBP}

The problems reported by the patient in ODI, were captured by the health professionals' scores in the linked ICF categories with a frequency of $11 \%$ to $98 \%$ (Table 4 ). The lowest frequency represented sexual functions (11\%). Otherwise the problems in body functions were captured by the health professionals with a frequency of $74 \%$ for $b 134$ Sleep functions and $98 \%$ for $b 280$ Sensation of pain. Problems in the ODI item walking was captured with a frequency of $41 \%$ to $56 \%$ dependent of which of the three linked ICF categories that were evaluated (Table 5). For the item travel, the problems were captured in $37 \%$ to $38 \%$ of the cases for the two linked categories, respectively. Personal ADL was linked to three categories and problems captured by $10 \%$ to $34 \%$, whereas

Table I The items in WHODAS II that could not be linked to specific categories in the ICF. Percentage of patients reporting problems in these items given

\begin{tabular}{lll}
\hline Items in WHODAS II & Reported problems by the patients (\%) & Linking to ICF \\
\hline $\begin{array}{l}\text { Self-care } \\
\text { Staying by oneself for some days }\end{array}$ & Not covered \\
$\begin{array}{l}\text { Participation } \\
\text { Barriers or hindrances in the world around }\end{array}$ & $49(40-58)$ & Environmental factors not specified \\
Living with dignity because of the attitudes & $44(35-54)$ & Environmental factors chapter 4 \\
and actions of others & $97(94-100)$ & Not covered \\
Time spent on health condition & $72(64-80)$ & Not covered \\
Drain on financial resources & $74(66-82)$ & Not covered \\
Problems for the family &
\end{tabular}

Abbreviations: ICF, International Classification of Functioning; WHODAS II, World Health Organization Disability Assessment Schedule II. 
Table 2 Percentage of patients $(\mathrm{Cl})$ reporting problems in the items of ODI andWHODAS II linked to ICF categories in the component of body functions. Percentage of patients $(\mathrm{Cl})$ having problems as reported by the health professionals in the Comprehensive ICF Core Set for LBP. The linked ODI items are named. The linked WHODAS II items are denoted by their numbers; the corresponding item text is found in Appendix I

\begin{tabular}{|c|c|c|c|}
\hline ICF categories & $\begin{array}{l}\text { Patients' self-reported } \\
\text { problems in ODI (\%) }\end{array}$ & $\begin{array}{l}\text { Patients' self-reported } \\
\text { problems in WHODAS II (\%) }\end{array}$ & $\begin{array}{l}\text { Problems as reported by } \\
\text { the Health professionals } \\
\text { in ICF Core Set LBP (\%) }\end{array}$ \\
\hline bI 34 Sleep functions & 89 (83-95) Sleeping & & $69(58-76)$ \\
\hline bl 40 Attention functions & & $36(27-45)$ DI.I & \\
\hline bl44 Memory functions & & $53(44-62)$ DI.2 & \\
\hline $\begin{array}{l}\text { bI } 52 \text { Emotionally affected } \\
\text { by the health condition }\end{array}$ & & $96(92-100)$ D6.5 & $42(33-5 I)$ \\
\hline b|64 Higher-level cognitive functions & & $50(4 \mathrm{I}-59) \mathrm{DI} .3$ & \\
\hline bI67 Mental functions of language & & $23(|5-3|)$ DI.5 & \\
\hline b280 Sensation of pain & 97 (94-100) Pain & & $91(86-96)$ \\
\hline b640 Sexual functions & 66 (57-75) Sex life & 55 (46-64) D4.5 & $14(7-2 \mid)$ \\
\hline
\end{tabular}

Abbreviations: $\mathrm{Cl}$, confidence interval; ICF, International Classification of Functioning; LBP, low back pain; ODI, Oswestry Disability Index; P.care, personal care; WHODAS II, World Health Organization Disability Assessment Schedule II.

social function was linked to three categories which captured problems with a frequency of $13 \%$ to $81 \%$. The problems reported by the patient in WHODAS II, were captured by the health professionals' scores in the linked ICF categories with a frequency of $13 \%$ to $97 \%$ (Table 6). Activities like standing, standing up and walking were generally captured by the health professionals, with a frequency from $66 \%$ to $97 \%$. However, problems with washing and dressing were missed to a larger extent and only noticed with a frequency of $27 \%$ and $30 \%$, respectively. For participation related problems, the items in WHODAS II were generally wider and linked to several ICF categories. When the linked ICF category was close in wording or concept to the question in WHODAS II like $d 640$ Doing housework or $d 850$ Remunerative work, the health professionals captured the problems with a frequency of $80 \%$ and $78 \%$, respectively. Problems with relationship were only captured in $21 \%$, whereas community integration was assessed with a frequency of $41 \%$ to $82 \%$ depending on the linked category (Table 6).

\section{Discussion}

All items in the ODI could be linked to the ICF and were also contained in the Comprehensive ICF Core Set for LBP. With respect to WHODAS II, some of the items in the participation domain could not be linked to the ICF, and several of the linked items were not contained in the Comprehensive ICF Core Set. When the patients reported problems within body functions, this was captured in above three quarter of the cases by the health professional with exception of problems with sexual functions. The patients' problems in activities and participations were generally also well reflected in the health professionals' scores. Surprisingly some of the problems in activities of daily living were an exception and poorly detected by the health professionals.

The development of the Comprehensive Core Set for LBP is based on a systematic review of the concepts in the outcome measurements for LBP (Brockow et al 2004), an empirical study (Ewert et al 2004) and a Delphi process with health professionals (Weigl et al 2004). In addition a formal consensus was performed (Cieza et al 2004). Based on this thorough approach, one would assume that the major problems of patients with LBP should be covered. The present results could also be taken in account for this view. On the other hand, some problems reported by a high number of the present patients were uncovered. This problem applies partly to the ICF classification and partly to the reduction of ICF categories in the present Comprehensive ICF Core Set. Our results indicate that patients with LBP experience the time spent on the health condition as a burden. The time dimension is not covered in the classification. Probably even more important is the consequences for the patients' economy. Although not directly linked to drain on the financial resources item, we would suggest that the ICF categories $d 870$ Economic self-sufficiency and e165 Assets may represent part of this problem and should be candidates for the Comprehensive ICF Core Set for LBP. The present patients also experience to be a burden to their families. This lack of the subjective 
Table 3 Percentage of patients $(\mathrm{Cl})$ reporting problems in the items of ODI andWHODAS II linked to ICF categories in the component of activities and participation. Percentage of patients $(\mathrm{Cl})$ having problems as reported by the health professionals in the Comprehensive ICF Core Set for LBP. The linked ODI items are named. The linkedWHODAS II items are denoted by their numbers; the corresponding item text is found in Appendix I

\begin{tabular}{|c|c|c|c|}
\hline ICF categories & $\begin{array}{l}\text { Patients' self-reported } \\
\text { problems in ODI (\%) }\end{array}$ & $\begin{array}{l}\text { Patients' self-reported } \\
\text { problems in WHODAS II (5) }\end{array}$ & $\begin{array}{l}\text { Problems as reported } \\
\text { by the health professionals } \\
\text { in ICF Core Set LBP (\%) }\end{array}$ \\
\hline dI55 Acquiring skills & & $35(26-44)$ DI.4 & \\
\hline dl 60 Focusing attention & & $36(27-45)$ DI.I & \\
\hline dI75 Solving problems & & $50(4 I-59)$ DI.3 & \\
\hline $\begin{array}{l}\text { d3 I0 Communicating with spoken } \\
\text { messages }\end{array}$ & & $23(|5-3|)$ DI.5 & \\
\hline d330 Speaking & & $27(19-35)$ DI.6 & \\
\hline d350 Conversation & & $27(19-35)$ DI.6 & \\
\hline d4I0 Changing basic body position & & $90(85-95)$ D2.2 & $76(68-84)$ \\
\hline d4I5 Maintaining a body position & $\begin{array}{l}93(88-98) \text { Sitting } \\
96(92-100) \text { Standing }\end{array}$ & $90(85-95)$ D2.I & $97(93-100)$ \\
\hline d430 Lifting and carrying objects & $96(92-100)$ Lifting & & $78(70-86)$ \\
\hline d450 Walking & 55 (46-64) Walking & $61(52-70)$ D2.5 & $50(4 I-59)$ \\
\hline $\begin{array}{l}\text { d460 Moving around in different } \\
\text { locations }\end{array}$ & 55 (46-64) Walking & $47(38-56)$ D2.3 & $37(28-46)$ \\
\hline d465 Moving around using equipment & 55 (46-64) Walking & & $40(31-49)$ \\
\hline d470 Using transportation & 9I (86-96) Traveling & & $39(30-48)$ \\
\hline d475 Driving & 9I (86-96) Traveling & & $40(31-49)$ \\
\hline d5 10 Washing oneself & 37(28-46) P. care & $4 I(32-50)$ D3.I & $20(13-27)$ \\
\hline d520 Caring for body parts & 37(28-46) P. care & & \\
\hline d530 Toileting & 37 (28-46) P. care & & $12(6-18)$ \\
\hline d540 Dressing & 37 (28-46) P. care & $47(38-56)$ D3.2 & $28(20-36)$ \\
\hline d550 Eating & & $3(0-6)$ D3.3 & \\
\hline $\begin{array}{l}\text { d620 Acquisition of goods } \\
\text { and services }\end{array}$ & & $67(58-76)$ D5.I & $33(25-42)$ \\
\hline d630 Preparing meals & & $67(58-76)$ D5.I & $26(18-34)$ \\
\hline d640 Doing housework & & $67(58-76)$ D5.I & $74(66-82)$ \\
\hline d650 Caring for household objects & & $67(58-76)$ D5.I & $51(42-60)$ \\
\hline d660 Assisting others & & $67(58-76)$ D5.I & $34(25-43)$ \\
\hline d720 Complex interpersonal & & $28(20-36) \mathrm{D} 4.3$ & \\
\hline interactions & & $\begin{array}{l}39(30-48) \text { D } 4.2 \\
43(34-52) \text { D.4.4 }\end{array}$ & \\
\hline d730 Relating with strangers & & $30(22-38)$ D4.I & \\
\hline d750 Informal social relationship & & $39(30-48) \mathrm{D} 4.2$ & \\
\hline d760 Family relationship & 74 (66-82) Social life & $28(20-36) \mathrm{D} 4.3$ & $13(7-19)$ \\
\hline d770 Intimate relationships & 74 (66-82) Social life & $28(20-36) \mathrm{D} 4.3$ & $17(10-24)$ \\
\hline d820 School education & & $84(76-92)$ D5.5 & \\
\hline d825 Vocational training & & $84(76-92)$ D5.5 & \\
\hline d830 Higher education & & $84(76-92)$ D5.5 & \\
\hline d840 Work preparation & & $84(76-92)$ D5.5 & \\
\hline $\begin{array}{l}\text { d845 Acquiring, keeping, } \\
\text { terminating a job }\end{array}$ & & $84(76-92)$ D5.5 & $46(37-55)$ \\
\hline
\end{tabular}


Table 3 (Continued)

\begin{tabular}{llll}
\hline ICF categories & $\begin{array}{l}\text { Patients' self-reported } \\
\text { problems in ODI (\%) }\end{array}$ & $\begin{array}{l}\text { Patients' self-reported } \\
\text { problems in WHODAS II (5) }\end{array}$ & $\begin{array}{l}\text { Problems as reported } \\
\text { by the health professionals } \\
\text { in ICF Core Set LBP (\%) }\end{array}$ \\
\hline d850 Remunerative employment & & $84(76-92)$ D5.5 & $72(64-80)$ \\
d855 Nonremunerative employment & & $84(76-92)$ D5.5 \\
d910 Community life & $74(66-82)$ Social life & $69(6 I-77)$ D6.I & $38(29-47)$ \\
d920 Recreation and leisure & $74(66-82)$ Social life & $73(65-8 I)$ D6.8 & $79(72-86)$ \\
d950 Political life & & $69(6 I-77)$ D6.I & \\
\hline
\end{tabular}

Abbreviations: $\mathrm{Cl}$, confidence interval; ICF, International Classification of Functioning; LBP, low back pain; ODI, Oswestry Disability Index; P.care, personal care; WHODAS II, World Health Organization Disability Assessment Schedule II.

dimension and autonomy in the ICF has also previously been criticized (Ueda and Okawa 2003; Hemmingsson and Jonsson 2005).

These aspects must first be handled by the ICF classification and does not directly apply to the development of the ICF Core Sets. It is worth to realize this shortcoming when applying the Comprehensive ICF Core Set for LBP in practice.
The present results also indicate that some important problems covered by the ICF classification disappear in the reduction of categories for the Comprehensive ICF Core Set for LBP. As many as 23 of the 47 categories linked to WHODAS II was left out, leaving 11 additional items in WHODAS II uncovered. Several of these items did not represent problems to the LBP patients, however, memory and cognitive problems was reported with a high frequency.

Table 4 Percentage of patients reporting problems in the items of ODI andWHODAS II linked to ICF categories. Percentage of patients reported by the health professionals to have barriers or facilitators in the linked ICF categories contained in the Comprehensive ICF Core Set for LBP. The linked ODI items are named. The linkedWHODAS II items are denoted by their numbers; the corresponding item text is found in Appendix I

\begin{tabular}{|c|c|c|c|}
\hline ICF categories & Linked to ODI (\%) & Linked to WHODAS II (\%) & $\begin{array}{l}\text { Barriers or facilitators as reported } \\
\text { by the health professionals } \\
\text { in ICF Core Set LBP (\%) }\end{array}$ \\
\hline $\begin{array}{l}\text { el I0 Products or substances } \\
\text { for personal consumption }\end{array}$ & & $3(0-6)$ D3.3 & $10(4-16)$ \\
\hline $\begin{array}{l}\text { el I } 5 \text { Products and technology } \\
\text { for personal use in daily living }\end{array}$ & & $3(0-6)$ D3.3 & \\
\hline $\begin{array}{l}\text { el } 20 \text { Products and technology } \\
\text { for personal indoor and outdoor } \\
\text { mobility and transportation }\end{array}$ & $\begin{array}{l}91 \text { (86-96) Traveling } \\
55 \text { (46-64) Walking }\end{array}$ & $47(38-56)$ D2.3 & $4(0-8)$ \\
\hline $\begin{array}{l}\text { el} 55 \text { Design, construction and } \\
\text { building products and technology, } \\
\text { private use }\end{array}$ & & $47(38-46)$ D2.3 & $3(0-6)$ \\
\hline e3 I0 Immediate family & & $28(20-36) \mathrm{D} 4.3$ & $13(6-19)$ \\
\hline $\begin{array}{l}\text { e520 Open space planning, services } \\
\text { and policies }\end{array}$ & & $47(38-56)$ D2.3 & \\
\hline $\begin{array}{l}\text { e540 Transportation services, systems } \\
\text { and polices }\end{array}$ & 9I(86-96) Traveling & & $9(4-14)$ \\
\hline $\begin{array}{l}\text { e585 Education and training services, } \\
\text { systems and polices }\end{array}$ & & $84(76-92)$ D5.5 & $5(0-9)$ \\
\hline $\begin{array}{l}\text { e } 590 \text { Labor and employment } \\
\text { services, systems and policies }\end{array}$ & & $84(76-92)$ D5.5 & $15(8-22)$ \\
\hline
\end{tabular}

Abbreviations: Cl, confidence interval; ICF, International Classification of Functioning; LBP, low back pain; ODI, Oswestry Disability Index; WHODAS II, World Health Organization Disability Assessment Schedule II. 
Table 5 Percentage of patients reporting a problem in the ODI captured by the Health Professional (HP) score in the linked ICF categories

\begin{tabular}{lll}
\hline ICF category & $\begin{array}{l}\text { Captured } \\
\text { by HP (\%) }\end{array}$ & Item in ODI \\
\hline bI34 Sleep functions & 74 & Sleeping \\
b280 Sensation of pain & 98 & Pain \\
b640 Sexual function & 1 I & Sex \\
d4I5 Maintaining a body position & 97 & Standing \\
& 94 & Sitting \\
d430 Lifting and carrying objects & 81 & Lifting \\
d450 Walking & 56 & Walking \\
d460 Moving around in different & 42 & Walking \\
locations & & \\
d465 Moving around using & 41 & Walking \\
equipment & & \\
d470 Using transportation & 37 & Travel \\
d475 Driving & 38 & Travel \\
d5 I0 Washing oneself & 21 & Personal ADL \\
d530 Toileting & 10 & Personal ADL \\
d540 Dressing & 34 & Personal ADL \\
d760 Family relationship & 13 & Social function \\
d770 Intimate relationship & 17 & Sex \\
d9 I0 Community life & 34 & Social function \\
d920 Recreation and leisure & 81 & Social function \\
\hline
\end{tabular}

Abbreviations: ADL, activities of daily living; ICF, International Classification of Functioning; ODI, Oswestry Disability Index.

Thus even though disorders in the low back is not considered to affect cognitive functions, it is well known that chronic pain may influence cognition (Jamison et al 1988; Glass and Park 2001). These aspects should therefore be taken into consideration in a revised Comprehensive ICF Core Set.

Resources and limitations in the environment is an aspect not taken much into consideration in the clinical assessment of LBP (Grotle et al 2005). Very few environmental aspects are included in clinical outcome measures for LBP, and when included, only as barriers. Hence comparison with the Comprehensive Core Set for LBP was difficult. We suggest that the inclusion of environmental factors in the Comprehensive Core Set for LBP represents an improvement to clinical practice. Physical as well as social barriers are important to identify, but facilitator are also to be noted. Several studies also document the importance of environmental resources for function and quality of life in patients with chronic diseases (Fisher and Weihs 2000; Grey et al 2006; Koleck et al 2006). Introducing the environmental factors into clinical practice in a systematic way, was regarded important by the health professionals scoring the patients' problems in the present study. Hence, there is a challenge to include the environmental factors in the development of outcome measures within this field.

We wanted to assess to which extent the health professional capture the individual patients' reported problems when they score the Comprehensive ICF Core Set for LBP. Comparing health professionals' scoring of patients' problems and the patients' self-reported problems is methodologically challenging (Perreault and Dionne 2006). The patients' reported problems may be influenced by their expectation of what they think might be of interest to the health professionals (Nordin et al 1998). The problems communicated by the patient may not be received or interpreted correctly by the health professionals (Parkin and Skinner 2003). The health professionals may be biased by their medical perspective of the consequences of LBP. In addition, the instruments used by the health professionals are not identical to the patients' self-report questionnaires. All these considerations also apply to the validation of this ICF Core Set for LBP. In addition, one single item of the ODI or WHODAS II was often linked to several categories in the Comprehensive ICF Core Set. Thus, the Comprehensive ICF Core Set represents a more detailed description of the problems in the different areas. The Comprehensive ICF Core Set represents a broader perspective to the problems of the LBP patients, as was the intention for the development of the ICF (WHO 2001).

On the other hand, the ICF categories could be linked to several items in ODI and WHODAS II, indicating that there is no complete overlap between the items and corresponding ICF categories. Thus, it is not surprising that the health professionals capture the patients' problems with a variable degree. Furthermore, function within some of the categories in ICF is observable, whereas other categories rely on patients' or other clinical information which may influence agreement. It is then worth to note the poor ability with which sexual problems and problems with intimate relationships were captured in the present study, whereas most other problems were noted to a much larger degree. Hence, the nature of the problem more than the differences in the content of items and corresponding ICF categories may explain this bias. Nevertheless it is important that the patients' problems are retained in instruments administered by health professionals, even though disagreement may be expected for several reasons.

ODI is scored on a six point Likert scale whereas WHODAS II and the Comprehensive ICF Core Set for LBP are scored on five point scales. The scorings were dichotomised into a problem or not. This cut off can be 
Table 6 Percentage of patients reporting a problem in the WHODAS II captured by the Health Professional (HP) score in the linked ICF categories

\begin{tabular}{lll}
\hline ICF category & Captured by HP (\%) & Items in WHODAS II \\
\hline b152 Emotional functions & 73 & D6.5 Emotionally affected by the condition \\
b640 Sexual function & 15 & D4.5 Sexual activities \\
d410 Changing basic body position & 76 & D2.2 Standing up from sitting down \\
d415 Maintaining a body position & 97 & D2.I Standing for long periods \\
d450 Walking & 65 & D2.5 Walking a long distance \\
d460 Moving around in different locations & 42 & D2.3 Moving around inside your home \\
d5 I0 Washing oneself & 27 & D3.I Washing \\
d540 Dressing & 30 & D3.2 Getting dressed \\
d620 Acquisition of goods and services & 38 & D5.I Taking care of household \\
d630 Preparing meals & 32 & D5.I Taking care of household \\
d640 Doing housework & 80 & D5.I Taking care of household \\
d650 Caring for household objects & 55 & D5.I Taking care of household \\
d660 Assisting others & 39 & D5.I Taking care of household \\
d760 Family relationship & 13 & D4.3 Getting along with people close \\
d770 Intimate relationship & 13 & D4.3 Getting along with people close \\
d845 Acquiring, keeping, terminating a job & 40 & D5.5 Day to day work/school \\
d850 Remunerative employment & 78 & D5.5 Day to day work/school \\
d9 I0 Community life & 41 & D6.I Joining in community activities \\
d920 Recreation and leisure & 82 & D6.8 Problems doing things for relaxation \\
\hline
\end{tabular}

Abbreviations: ICF, International Classification of Functioning;WHODAS II, World Health Organization Disability Assessment Schedule II.

questioned and certainly makes it difficult to evaluate the correspondence between health professionals and patients' agreement on the severity of problems. This is an important aspect which should be investigated by proper methods in further research. The extent to which the health professionals captured the patients' reported problems varied considerably. The correspondence was higher for physical functions than for the emotional and relational aspects, as well as for sexual function. Problems with physical function may be easier to observe and assess in the clinical situation. There may be a discrepancy in perspectives between the clinicians' general knowledge about a disorder like LBP and the patients' specific, self-experienced knowledge. The health professionals may be using their own norms when evaluating phenomenon like concentration and participation in the community, whereas the patients may have lower requirements for these functions. Nevertheless, emotional and sexual problems may influence quality of life, and an improvement in assessing these aspects is needed in clinical practice. Qualitative methodology may be needed in order to guide development of better assessment strategies for these aspects.
A convenience sample of patients was included, and the exact eligible numbers not recorded. This strategy may have influenced the results. Nevertheless the sample seemed to report comparable pain and disability with previous Norwegian studies with representative populations (Holm et al 2003; Storheim et al 2003; Grotle et al 2006). Furthermore, intra- and inter-rater reliability was not investigated regarding the ICF scoring in the present study. However, fair reliability is reported for the ICF Core Set for rheumatoid arthritis (Uhlig et al 2007).

\section{Conclusion}

The Comprehensive ICF Core Set for LBP covers most of the items in ODI and WHODAS II in areas where patients report significant problems with some exceptions. The subjective dimension related to the impact of the health condition as well as the feeling of being a burden to their family appeared to be important to these patients and not covered in the ICF. Problems with sexual functions and relationship were poorly reflected in the health professionals' scores in the Comprehensive ICF Core Set for LBP. In clinical practice it is a challenge to assess the individual patients' broad spectrum of problems precisely. 


\section{Acknowledgments}

We thank the participating health professional at the study centers at the Department of Physical Medicine and Rehabilitation Haukeland University Hospital, the Haugland Centre, Hernes Institute and Department of Physical Medicine and Rehabilitation Ulleval University Hospital for data collection and contribution to valuable discussions about the Comprehensive ICF Core Set. We thank Susan Schanke for skillful help with the language, the participation patients and finally the Directory of Health in Norway for financial support.

\section{References}

Bongers PM, de Winter CR, Kompier MAJ, et al. 1993. Psychosocial factors at work and musculoskeletal disease. Scand $J$ Work Environ Health, 19:297-312.

Brage S. 1998. Musculoskeletal health problems and sickness absence. Thesis, Institute of General Practice and Community Medicine, Oslo University.

Brockow T, Cieza A, Kuhlow H, et al. 2004. Identifying the concepts contained in outcome measures of clinical trials on musculoskeletal disorders and chronic widespread pain using the International Classification of Functioning, Disability and Health as a reference. $J$ Rehabil Med, (Suppl 44):30-6.

Cieza A, Geyh S, Chatterji S, et al. 2005. ICF linking rules: an update based on lessons learned. J Rehabil Med, 37:212-8.

Cieza A, Stucki G, Weigl M, et al. 2004. ICF Core Sets for low back pain. J Rehabil Med, (Suppl 44):69-74.

Daltroy LH, Cats-Baril WL, Katz JN, et al. 1996. The North American spine society lumbar spine outcome assessment Instrument: reliability and validity tests. Spine, 21:741-9.

Ewert T, Fuessl M, Cieza A, et al. 2004. Identification of the most common patient problems in patients with chronic conditions using the ICF checklist. J Rehabil Med, (Suppl 44):22-9.

Fairbank JC, Pynsent PB. 2000. The Oswestry Disability Index. Spine, 25:2940-52.

Fisher L, Weihs KL. 2000. Can addressing family relationships improve outcomes in chronic disease? Report of the National Working Group on Family-Based Interventions in Chronic Disease. J Fam Pract, 49:561-6.

Glass JM, Park DC. 2001. Cognitive dysfunction in fibromyalgia. Curr Rheumatol Rep, 3:123-7.

Grey M, Knafl K, McCorkle R. 2006. A framework for the study of self- and family management of chronic conditions. Nurs Outlook, 54:278-86.

Grill E, Ewert T, Chatterji S, et al. 2005. ICF Core Sets development for the acute hospital and early post-acute rehabilitation facilities. Disabil Rehabil, 27(7-8):361-6.

Grotle M, Brox JI, Vollestad NK. 2003. Cross-cultural adaptation of the Norwegian versions of the Roland-Morris Disability Questionnaire and the Oswestry Disability Index. J Rehabil Med, 35:241-7.

Grotle M, Brox JI, Vollestad NK. 2005. Functional status and disability questionnaires: what do they assess? A systematic review of backspecific outcome questionnaires. Spine, 30:130-40.
Grotle M, Vollestad NK, Brox JI. 2006. Clinical course and impact of fear-avoidance beliefs in low back pain: prospective cohort study of acute and chronic low back pain: II. Spine, 31:1038-46.

Guyatt GH, Feeny DH, Patrick DL. 1993. Measuring health-related quality of life. Ann Intern Med, 118:622-9.

Hemmingsson H, Jonsson H. 2005. An occupational perspective on the concept of participation in the International Classification of Functioning, Disability and Health - some critical remarks. Am J Occup Ther, 59:569-76.

Holm I, Friis A, Storheim K, et al. 2003. Measuring self-reported functional status and pain in patients with chronic low back pain by postal questionnaires: a reliability study. Spine, 28:828-33.

Jamison RN, Sbrocco T, Parris WCV. 1988. The influence of problems with concentration and memory on emotional distress and daily activities in chronic pain patients. Int J Psychiatry Med, 18:183-90.

Jeffries LJ, Milanese SF, Grimmer-Somers KA. 2007. Epidemiology of adolescent spinal pain: a systematic overview of the research literature. Spine, 32:2630-7.

Koleck M, Mazaux JM, Rascle N, et al. 2006. Psycho-social factors and coping strategies as predictors of chronic evolution and quality of life in patients with low back pain: a prospective study. Eur J Pain, 10:1-11.

Mullis R, Barber J, Lewis M, et al. 2007. ICF core sets for low back pain: do they include what matters to patients? J Rehabil Med, 39:353-7.

Natvig B, Picavet HS. 2002. The epidemiology of soft tissue rheumatism. Best Pract Res Clin Rheumatol, 16:777-93.

Nordin M, Cedraschi C, Skovron ML. 1998. Patient-health care provider relationship in patients with non-specific low back pain: a review of some problem situations. Baillieres Clin Rheumatol, 12:75-92.

Parkin T, Skinner TC. 2003. Discrepancies between patient and professionals recall and perception of an outpatient consultation. Diabet Med, 20:909-14.

Perreault K, Dionne CE. 2006. Does patient-physiotherapist agreement influence the outcome of low back pain? A prospective cohort study. BMC Musculoskelet Disord, 7:76.

Roland M, Fairbank J. 2000. The Roland-Morris Disability Questionnaire and the Oswestry Disability Questionnaire. Spine, 25:3115-24.

Sigl T, Cieza A, Brockow T, et al. 2006. Content comparison of low back pain-specific measures based on the International Classification of Functioning, Disability and Health (ICF). Clin J Pain, 22:147-53.

Storheim K, Brox JI, Holm I, et al. 2003. Intensive group training versus cognitive intervention in sub-acute low back pain: short-term results of a single-blind randomized controlled trial. J Rehabil Med, 35:132-40.

Ueda S, Okawa Y. 2003. The subjective dimension of functioning and disability: what is it and what is it for? Disabil Rehabil, 25(11-12):596-601.

Uhlig T, Lillemo S, Moe RH, et al. 2007. Reliability of the ICF Core Set for rheumatoid arthritis. Ann Rheum Dis, 66:1078-84.

Weigl M, Cieza A, Andersen C, et al. 2004. Identification of relevant ICF categories in patients with chronic health conditions: a Delphi exercise. J Rehabil Med, (Suppl 44):12-21.

[WHO] World Health Organization. 2001. International Classification of Functioning, Disability and Health: ICF. Geneva, Switzerland: World Health Organization.

[WHODAS II] World Health Organization. 2001. World Health Organization Disability Assessment Schedule II [online]. Geneva, Switzerland: World Health Organization. Accessed on October 10, 2008. URL: http://www. who.int/icidh/whodas/index.html. 


\section{Appendix I}

\section{The items eligible for linking in WHODAS II (200I)} World Health Organization Disability Assessment Schedule II

D1.1 Concentrating on doing something for ten minutes

D1.2 Remembering to do important things

D1.3 Analyzing and finding solutions to problems in day to day life

D1.4 Learning a new task, for example, learning how to get to a new place

D1.5 Generally understanding what people say

D1.6 Starting and maintaining a conversation?

D2.1 Standing for long periods such as 30 minutes

D2.2 Standing up from sitting down

D2.3 Moving around inside your home

D2.4 Getting out of your home

D2.5 Walking a long distance such as a kilometre (or equivalent)

D3.1 Washing your whole body

D3.2 Getting dressed

D3.3 Eating

D3.4 Staying by yourself for a few days

D4.1 Dealing with people you do not know

D4.2 Maintaining a friendship?

D4.3 Getting along with people who are close to you

D4.4 Making new friends
D4.5 Sexual activities

D5.1 Taking care of your household responsibilities

D5.2 Doing most important household tasks well

D5.3 Getting all the household work done that you needed to do

D5.4 Getting your household work done as quickly as needed

D5.5 Your day to day work/school

D5.6 Doing your most important work/school tasks well

D5.7 Getting all the work done that you need to do

D5.8 Getting your work done as quickly as needed

D6.1 How much of a problem did you have in joining in community activities (for example, festivities, religious or other activities) in the same way as anyone else can?

D6.2 How much of a problem did you have because of barriers or hindrances in the world around you?

D6.3 How much of a problem did you have living with dignity because of the attitudes and actions of others?

D6.4 How much time did you spend on your health condition, or its consequences?

D6.5 How much have you been emotionally affected by your health condition?

D6.6 How much has your health been a drain on the financial resources of you or your family?

D6.7 How much of a problem did your family have because of your health problems?

D6.8 How much of a problem did you have in doing things by yourself for relaxation or pleasure? 
